Check for updates

Cite this: RSC Adv., 2019, 9, 10789

Received 14th February 2019

Accepted 26th March 2019

DOI: 10.1039/c9ra01149h

rsc.li/rsc-advances

\section{Rational design of quinoxaline-based bipolar host
materials for highly efficient red phosphorescent \\ Rational design of quinoxaline-based bipolar host
materials for highly efficient red phosphorescent organic light-emitting diodes $\uparrow$}

\author{
Zilong Feng, $\dot{\dagger}^{\mathrm{a}}$ Zhixiang Gao, $\mathbb{D} \dot{t}^{* a b}$ Wenshan $Q u,{ }^{* b}$ Tingting Yang, ${ }^{\mathrm{b}}$ Jiangang $\mathrm{Li}^{\mathrm{b}}$ \\ and Lixiong Wang ${ }^{a}$
}

Two novel bipolar carbazole/diphenylquinoxaline-based host materials 3-(2,3-diphenylquinoxalin-6-yl)-9phenyl-9H-carbazole (M1) and 3-(4-(2,3-diphenylquinoxalin-6-yl)phenyl)-9-phenyl-9H-carbazole (M2) have been rationally designed and synthesized. The phenyl spacer between the functionalized quinoxaline moiety and the carbazole moiety is also introduced to investigate its influence on their photophysical properties. The chemical structures, and thermal, photophysical and electrochemical properties of the two host materials were characterized and explored in detail. Red phosphorescent light-emitting diodes with $\mathrm{M} 1$ and $\mathrm{M} 2$ as hosts were prepared to explore their electroluminescent properties. Both M1 and M2 host-based red devices exhibit outstanding electroluminescent performance. For example, two red devices all realize good red emission with the maximum at $594 \mathrm{~nm}$, the maximum external quantum efficiency and luminance can reach $14.66 \%$ and $28619 \mathrm{~cd} \mathrm{~m}^{-2}$ for M1based devices and $15.07 \%$ and $28818 \mathrm{~cd} \mathrm{~m}^{-2}$ for M2-based devices, indicating compounds M1 and M2 designed in this work have potential applications in the development of high-performance monochrome and white OLEDs.

\section{Introduction}

In recent years, owing to their fascinating commercial potential in the fields of flexible displays and solid state lighting, organic light-emitting diodes (OLEDs) have attracted great attention. ${ }^{1-7}$ Organic electroluminescent materials have been developed and have been extensively studied. ${ }^{8-17}$ Later Forrest and co-authors found that transition-metal complexes are a new class of highly efficient phosphorescent materials. ${ }^{18-20}$ Phosphorescent OLEDs, with phosphors as emitters, can simultaneously capture singlet excitons and triplet excitons excited by an electric field. Their internal quantum efficiency can exceed the theoretical limit of $25 \%$ in OLEDs based on fluorescent materials, making it possible to realize the unit internal quantum efficiency (IQE). So, phosphors and phosphorescent OLEDs are one of the main development directions in the future of organic electroluminescence. ${ }^{21-32}$

\footnotetext{
${ }^{a}$ School of Architecture, Tianjin University, Tianjin 300072, PR China. E-mail: gao_zhixiang@126.com

${ }^{b}$ Shanxi Province Key Laboratory of Microstructure Functional Materials, Institute of Solid State Physics, Shanxi Datong University, Datong 037009, P. R. China. E-mail: wenshanqu@126.com

$\dagger$ Electronic supplementary information (ESI) available. See DOI: 10.1039/c9ra01149h

\$ These authors contributed equally to this work.
}

The red emission component is an integral part of both highquality solid state lightings and displays. ${ }^{33-39}$ The performance of red phosphorescent OLEDs is not determined by phosphors themselves, but also closely related to the host materials. Bipolar host materials that could balance the carriertransportations for improving the efficiency of phosphorescent OLEDs have become the current research focus. Many bipolar host materials have been explored in highly efficient red phosphorescent OLEDs, especially in the design of acceptor moieties. ${ }^{40-42}$ Recently, diphenylquinoxaline derivatives showing excellent electron-transportation property also have been selected as the novel acceptor moiety to realize the bipolar host materials. ${ }^{33,34}$ For instance, Cheng et al. designed an excellent bipolar host material which is composed of two $6 \mathrm{H}$ indolo $[2,3-b]$ quinoxaline unit bridged by the tetraphenylsilane core realizing high-efficiency red phosphorescent OLEDs. ${ }^{33}$ It is still necessary to further explore the quinoxaline-based bipolar host materials.

Herein, we designed two novel host materials (M1 and M2) by combining the quinoxaline moiety and carbazole moiety, with various linkage ways between carbazole and quinoxaline moiety. Red phosphorescent OLEDs with M1 and M2 as hosts were successfully fabricated, and both M1 and M2 hosts-based red devices exhibit the outstanding electroluminescent performance. For example, the maximum external quantum efficiency (EQE) and luminance reach $14.66 \%$ and $28619 \mathrm{~cd} \mathrm{~m}^{-2}$ for M1- 
based red device, $15.07 \%$ and $28818 \mathrm{~cd} \mathrm{~m}^{-2}$ for M2-based red device.

\section{Experimental}

\section{General experimental information}

The detailed information on the solvents, chemicals, and general experiments can be found in the ESI. $\dagger$

\section{Synthesis of bipolar host materials}

The synthesis of 3-(2,3-diphenylquinoxalin-6-yl)-9-phenyl9H-carbazole (M1). 3-Bromo-9-phenyl-9H-carbazole (1.5 g, 4.7 mmol), 2,3-diphenyl-6-(4,4,5,5-tetramethyl-1,3,2-dioxaborolan2-yl)quinoxaline (1.9 g, $4.7 \mathrm{mmol}), \mathrm{K}_{2} \mathrm{CO}_{3}(1.4 \mathrm{~g}, 10 \mathrm{mmol})$, tetrakis(triphenylphosphine)palladium $(50 \mathrm{mg})$ and $\mathrm{H}_{2} \mathrm{O}(15$ $\mathrm{mL}$ ) were dissolved in THF $(50 \mathrm{~mL})$. The mixture was allowed to reflux under $\mathrm{N}_{2}$ for $18 \mathrm{~h}$. After the reaction completed, the mixture was cooled, then extracted with methylene chloride, dried over anhydrous $\mathrm{Na}_{2} \mathrm{SO}_{4}$ and concentrated. The crude product was purified by column chromatography (petroleum ether: dichloromethane $=2: 1$ ) to obtain a solid powder (yield $81 \%) .{ }^{1} \mathrm{H}$ NMR $\left(400 \mathrm{MHz}, \mathrm{CDCl}_{3}\right) \delta=8.60(\mathrm{~d}, J=1.60 \mathrm{~Hz}, 1 \mathrm{H})$, $8.53(\mathrm{~d}, J=1.60 \mathrm{~Hz}, 1 \mathrm{H}), 8.29-8.22(\mathrm{~m}, 3 \mathrm{H}), 7.88(\mathrm{dd}, J=8.40$, $2.00 \mathrm{~Hz}, 1 \mathrm{H}), 7.67-7.61(\mathrm{~m}, 4 \mathrm{H}), 7.58-7.49$ (m, 6H), 7.47-7.44 $(\mathrm{m}, 2 \mathrm{H}), 7.39-7.33(\mathrm{~m}, 7 \mathrm{H}) .{ }^{13} \mathrm{C}$ NMR $\left(101 \mathrm{MHz}, \mathrm{CDCl}_{3}\right) \delta=$ 153.75 , 152.83, 143.62, 141.51, 141.50, 140.93, 140.27, 139.01, 138.98, 137.48, 131.68, 130.18, 130.02, 129.92, 129.90, 129.35, $128.91,128.85,128.33$, 128.32, 127.73, 127.12, 126.42, 125.92, $125.60,124.17,123.40,120.41,119.36,110.44,110.08$. HRMS (ESI, $m / z):[\mathrm{M}+\mathrm{H}]^{+}$calcd for $\mathrm{C}_{38} \mathrm{H}_{26} \mathrm{~N}_{3}, 524.2127$, found 524.2133. Anal. calcd for $\mathrm{C}_{38} \mathrm{H}_{25} \mathrm{~N}_{3}$ : C 87.16, $\mathrm{H}$ 4.81, N 8.02; found: C 87.12, H 4.90, N 8.09.

The synthesis of 3-(4-(2,3-diphenylquinoxalin-6-yl)phenyl)-9phenyl-9H-carbazole (M2). Compound M2 was synthesized by the same procedure for M1 using 3-(4-bromophenyl)-9-phenyl$9 \mathrm{H}$-carbazole as starting material. Yield: $76 \%$. ${ }^{1} \mathrm{H}$ NMR (400
$\left.\mathrm{MHz}, \mathrm{CDCl}_{3}\right) \delta=8.49(\mathrm{~d}, J=1.60 \mathrm{~Hz}, 1 \mathrm{H}), 8.45(\mathrm{~d}, J=1.60 \mathrm{~Hz}$, $1 \mathrm{H}), 8.28(\mathrm{~d}, J=8.80 \mathrm{~Hz}, 1 \mathrm{H}), 8.23(\mathrm{~d}, J=7.60 \mathrm{~Hz}, 1 \mathrm{H}), 8.15(\mathrm{dd}, J$ $=8.80,2.00 \mathrm{~Hz}, 1 \mathrm{H}), 7.95-7.89(\mathrm{~m}, 4 \mathrm{H}), 7.75(\mathrm{dd}, J=8.40$, $2.00 \mathrm{~Hz}, 1 \mathrm{H}), 7.67-7.60(\mathrm{~m}, 4 \mathrm{H}), 7.58-7.54(\mathrm{~m}, 4 \mathrm{H}), 7.52-7.48$ $(\mathrm{m}, 2 \mathrm{H}), 7.45(\mathrm{~d}, J=3.60 \mathrm{~Hz}, 2 \mathrm{H}), 7.40-7.32(\mathrm{~m}, 7 \mathrm{H})$. HRMS (ESI, $m / z):[\mathrm{M}+\mathrm{H}]^{+}$calcd for $\mathrm{C}_{44} \mathrm{H}_{33} \mathrm{~N}_{3}, 600.2440$, found 600.2439 . Anal. calcd for $\mathrm{C}_{44} \mathrm{H}_{29} \mathrm{~N}_{3}$ : C 88.12, H 4.87, N 7.01; found: C 88.19, H 4.92, N 7.05.

\section{OLED fabrication and measurement}

All OLEDs were deposited on the indium-tin-oxide (ITO)/glass substrates with a sheet resistance of $15 \Omega$ per square by thermal evaporation technique. ITO/glass substrates were cleaned sequentially by detergent, de-ionized water, acetone and isopropanol. The cleaned ITO/glass substrates were dried by nitrogen $\left(\mathrm{N}_{2}\right)$ flow and treated by ultraviolet. Then ITO/glass substrates were loaded into the evaporator with 13-evaporation sources. When the pressure in evaporator is below $5.0 \times 10^{-4}$ $\mathrm{Pa}$, the evaporation sources are heated for device fabrication. The deposition rate and film thickness were monitored controlled by the calibrated crystal quartz sensors. And the deposition rates for organic materials, $\mathrm{MoO}_{3}, \mathrm{LiF}$, and $\mathrm{Al}$ were controlled at about $1 \AA \mathrm{s}^{-1}, 0.3 \AA \mathrm{s}^{-1}, 0.1 \AA \mathrm{s}^{-1}$, and $3-6 \AA_{\mathrm{s}}^{-1}$, respectively. The overlap between the $\mathrm{Al}$ and ITO is $3.0 \times 3.0$ $\mathrm{mm}^{2}$, defined as an active area.

The electroluminescence (EL) spectra and Commission Internationale de L'Eclairage (CIE) coordinates for OLEDs were recorded by a computer controlled PR-655 spectra scan spectrometer. The current-voltage-luminance $(J-V-L)$ characteristics, current efficiency, and power efficiency were measured by a computer-controlled Keithley 2400 source integrated with a BM-70A luminance meter. The EQE was calculated from the EL spectra and $J-V-L$ data. All samples were tested immediately after thin films deposition without encapsulation at room temperature in ambient atmosphere.

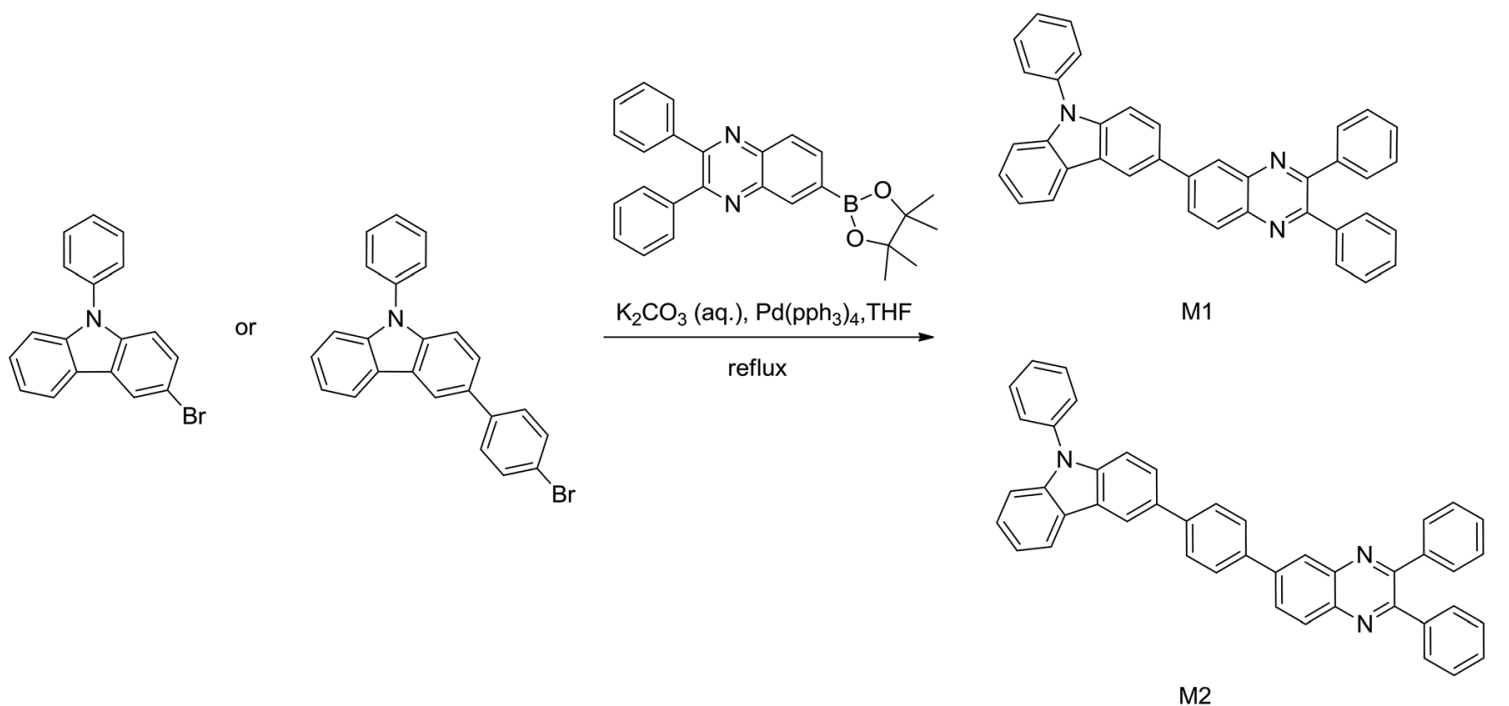

Scheme 1 The synthetic routes of bipolar host materials M1 and M2. 


\section{Result and discussion}

\section{Synthesis and characterization}

The detailed synthetic routes and chemical structures of bipolar host materials are shown in Scheme 1. The synthesis of M1 and M2 was realized through Suzuki coupling reaction by reacting 3-bromo-9-phenyl-9H-carbazole or 3-(4-bromophenyl)-9-phenyl-9H-carbazole with 2,3-diphenyl-6- $(4,4,5,5$ tetramethyl-1,3,2-dioxaborolan-2-yl)quinoxaline, respectively in high yields (over 75\%). Both two compounds were confirmed by high-resolution mass spectra and nuclear magnetic resonance spectra (shown in ESI $\dagger$ ). Under a nitrogen atmosphere, using the TGA and DSC to characterize the thermal properties of compounds M1 and M2. As shown in Fig. 1 and Table 1, the onset decomposition temperature ( $T_{\mathrm{d}}$, corresponding to $5 \%$ weight loss) according to the TGA data is $321{ }^{\circ} \mathrm{C}$ for $\mathbf{M 1}$ and is $415{ }^{\circ} \mathrm{C}$ for $\mathbf{M 2}$. We obviously found that the endothermic glass transition temperature $\left(T_{\mathrm{g}}\right)$ for $\mathbf{M 1}$ and $\mathbf{M 2}$ is determined to be $176{ }^{\circ} \mathrm{C}$ and $218{ }^{\circ} \mathrm{C}$ by analyzing the DSC traces, indicating $\mathbf{M 1}$ and M2 compounds are suitable for developing OLEDs by thermal evaporation technology. Owing to its much more steric structure of the molecule, the host M2 shows obviously both high $T_{\mathrm{g}}$ and $T_{\mathrm{d}}$ values. The relatively high thermal stabilities of the host materials are benefit for improving the morphology of the film and lifetime of the device by suppressing the phase separation and crystallization during the operation process of device.

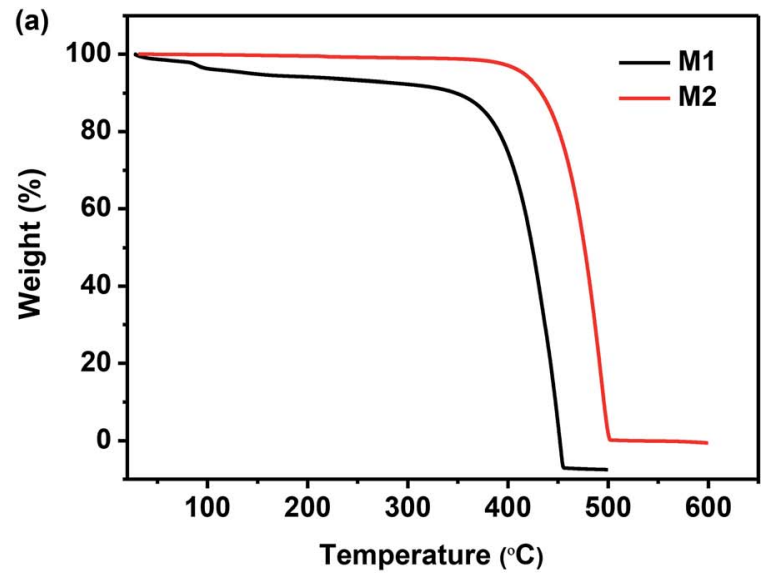

\section{Photophysical properties}

The absorption and emission properties of M1 and M2 were investigated in toluene. As depicted in Fig. 2a, the absorption of $\mathbf{M 1}$ and M2 exhibits bands in the range from 250 to $430 \mathrm{~nm}$ (247, 298, $387 \mathrm{~nm}$ for M1; 254, 303, $378 \mathrm{~nm}$ for M2), attributed to the $\pi-\pi^{*}$ electronic transition of the quinoxaline and carbazole unit. ${ }^{33,34,40-42}$ M1 and $\mathbf{M 2}$ show almost the same absorption spectra in spite of the larger $\pi$-electron conjugation of compound $\mathbf{M} 2$, implying that the introduction of the phenyl spacer almost has little effect on the absorption properties of these donor-acceptor systems.

However, quite different from their absorption properties, two compounds exhibited the different maximum emission wavelength $\left(\lambda_{\max }^{\mathrm{em}}=493 \mathrm{~nm}\right.$ for M1; $\lambda_{\max }^{\mathrm{em}}=518 \mathrm{~nm}$ for M2) in toluene at room temperature, as depicted in Fig. 2a and Table 1. The slight red shifted in the emission of $\mathbf{M} 2$ could be attributed to the larger $\pi$-electron conjugation. The compounds $\mathbf{M 1}$ and M2 exhibited sky-blue or green fluorescence with energy gap of 2.51 and $2.39 \mathrm{eV}$ in toluene, implying that the $\pi$-electron conjugation and co-planarity of molecule have been tuned by the phenyl spacer between functionalized quinoxaline moiety and carbazole moiety. In addition, the low temperature phosphorescence spectra of the compound M1 and M2 were also recorded at $77 \mathrm{~K}$ to calculate the triplet energies. As shown in the Fig. $2 \mathrm{~b}$, the low temperature phosphorescence spectra of both compounds were almost the same. The maximum emission of the phosphorescence spectra was at the wavelength of $553 \mathrm{~nm}$. The triplet energy levels were calculated by the first emission peak of the low-temperature phosphorescence spectra

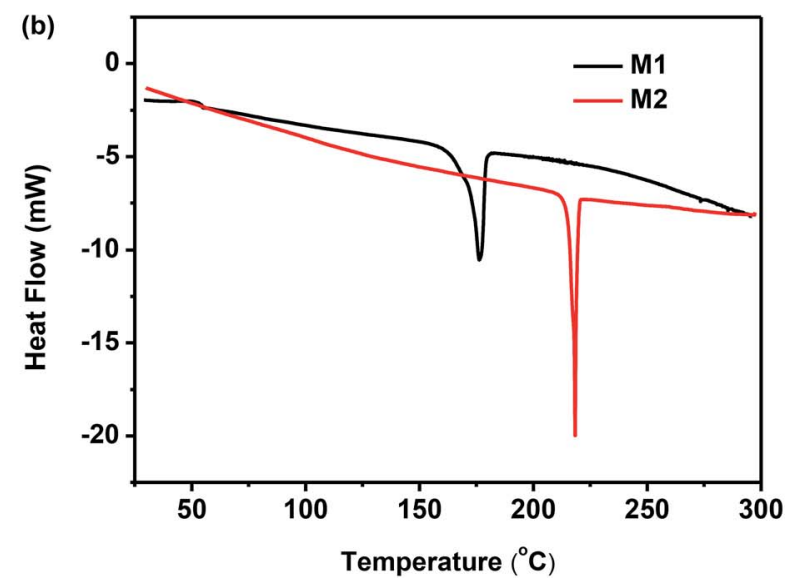

Fig. 1 The thermogravimetric (a) and differential scanning calorimetry (b) analysis of bipolar host materials M1 and M2.

Table 1 Photophysical properties of the bipolar host materials M1 and M2

\begin{tabular}{|c|c|c|c|c|c|c|c|c|c|c|}
\hline Compound & $\lambda_{\max }^{\mathrm{abs}} / \lambda_{\text {onset }}{ }^{a}[\mathrm{~nm}]$ & $\lambda_{\max }^{\mathrm{em} a}[\mathrm{~nm}]$ & $\lambda_{\text {phos }}^{b}[\mathrm{~nm}]$ & $E_{\mathrm{g}}{ }^{c}[\mathrm{eV}]$ & $E_{\mathrm{T}}^{d}[\mathrm{eV}]$ & $E_{\text {onset }}[\mathrm{V}]$ & $\mathrm{HOMO}^{e}[\mathrm{eV}]$ & $\operatorname{LUMO}^{f}[\mathrm{eV}]$ & $T_{\mathrm{d}}{ }^{g}\left[{ }^{\circ} \mathrm{C}\right]$ & $T_{\mathrm{g}}{ }^{h}\left[{ }^{\circ} \mathrm{C}\right]$ \\
\hline M1 & $247,298,387$ & 493 & 553 & 2.51 & 2.24 & 1.20 & -5.60 & -3.09 & 321 & 176 \\
\hline M2 & $254,303,378$ & 518 & 553 & 2.39 & 2.24 & 1.20 & -5.60 & -3.21 & 415 & 218 \\
\hline
\end{tabular}

${ }^{a}$ Measured in toluene at room temperature. ${ }^{b}$ Measured in toluene at $77 \mathrm{~K} .{ }^{c}$ Calculated by the equation $E_{\mathrm{g}}^{\mathrm{Opt}}=1240 / \lambda_{\max }^{\mathrm{em}}{ }^{d} \mathrm{Calculated}$ by the first

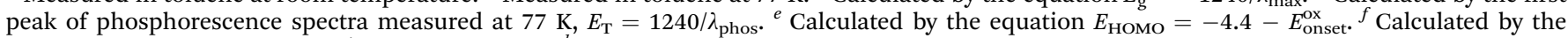
equation $E_{\mathrm{LUMO}}=E_{\mathrm{HOMO}}+E_{\mathrm{g} .}{ }^{g}$ Measured by TGA. ${ }^{h}$ Measured by DSC. 
(a)

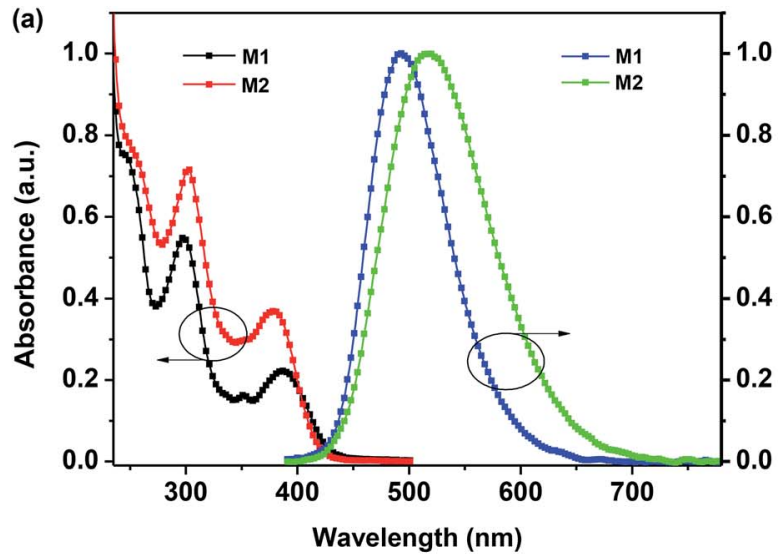

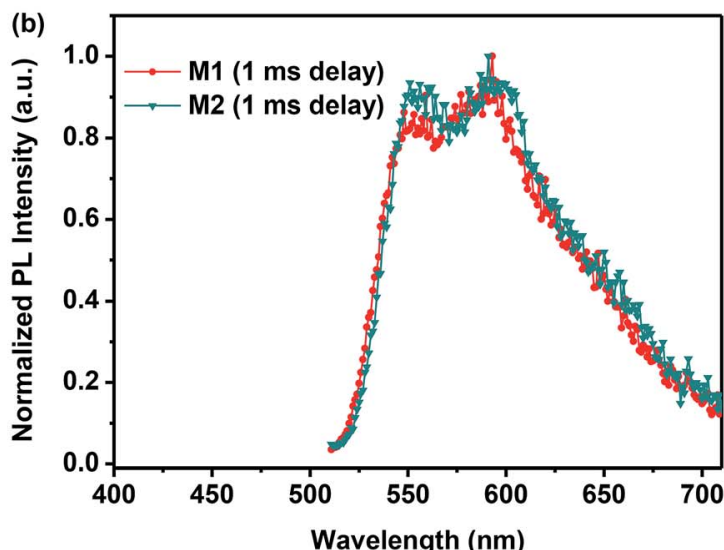

Fig. 2 (a) UV-Vis absorption and PL spectra of the compounds M1 and M2 in toluene at $297 \mathrm{~K}$; (b) phosphorescence spectra of the compound M1 and $\mathrm{M} 2$ at $77 \mathrm{~K}$.

and were determined to be $2.24 \mathrm{eV}$, which is suitable for the red OLEDs. ${ }^{24}$ In addition, at the $77 \mathrm{~K}$, we can observe the electronic transitions between the $\mathrm{T}_{1}$ substates (substates III, II, I) and the ground state $S_{0}$. From the intensity distribution, it can be concluded that the radiative transition from the lowest substate I to the ground state $S_{0}$ is largely forbidden, while the transitions from the two higher-lying substates III and II to the ground state are significantly more allowed.

\section{Electrochemical properties}

As depicted in Fig. 3, using a standard three-electrode electrochemical cell in an electrolyte solution, the electrochemical behavior of compounds M1 and M2 was investigated by cyclic voltammetry. The energy level of the highest occupied molecular orbital (HOMO) for M1 and M2 were calculated to be both $-5.60 \mathrm{eV}$ from the onset potentials of oxidation peak, while the energy level of the lowest unoccupied molecular orbital (LUMO) of these host materials were determined to be -3.09 and

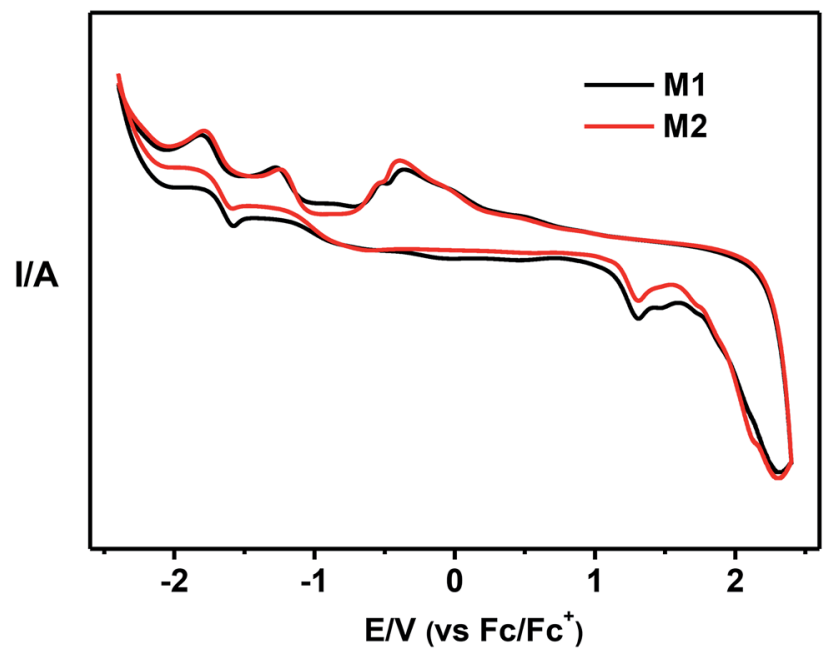

Fig. 3 The cyclic voltammograms of compounds M1 and M2.
$-3.21 \mathrm{eV}$ according to the band gap energy $\left(E_{\mathrm{g}}\right)$ and HOMO energy level. The data of $E_{\mathrm{g}}$ and HOMO/LUMO energy levels were listed in Table 1. The same HOMO levels of both compounds can be explained by sharing the same electrondonor carbazole group, which indicated that the phenyl spacer between the functionalized quinoxaline moiety and carbazole moiety has no effect on the HOMO levels. However, the LUMO energy of compound M1 $(-3.09 \mathrm{eV})$ were higher than that of M2 $(-3.21 \mathrm{eV})$, implying that the phenyl spacer have evident influence on the LUMO of these donor-acceptor systems. ${ }^{\text {40-42 }}$

\section{Red phosphorescent OLEDs}

Considering the triplet energy levels $(2.24 \mathrm{eV})$ of $\mathbf{M 1}$ and M2 is suitable for red OLEDs, to order to prove their potential application in OLEDs, two doped device of ITO/40 nm-poly(3,4ethylenedioxythiophene):poly(styrenesulfonate) (PEDOT:PSS) layer/45 nm-di-(4-( $N, N$-di- $p$-tolyl-amino)-phenyl)cyclohexane (TAPC) layer/5 nm-4, $4^{\prime}, 4^{\prime \prime}$-tris(carbazol-9-yl)triphenylamine (TCTA) layer/20 nm-hosts: 5\% wt bis(2-phenylquinolinato)acetylacetonate iridium(III) (Ir(pq) $)_{2}$ acac) layer/55 nm-1,3,5tri((3-pyridyl)-phen-3-yl)benzene (TmPyPB) layer/0.8 nmlithium fluoride (LiF) layer/80 $\mathrm{nm}$-aluminum (Al) layer were fabricated by vacuum thermal deposition, where hosts are M1 and M2, corresponding to the device R1 and R2, respectively. The device structure and organic molecules used in device fabrication are displayed in Fig. 4. In two red devices, different function materials were chosen on the basis of knowing the energy level of materials, and the thickness of different layers was decided by combining the reported relevant literature and mobility of materials. ${ }^{\mathbf{4 , 6 , 2 5}}$ In these devices, ITO was used as an anode; the $\mathrm{LiF} / \mathrm{Al}$ layers were employed as a composite cathode; $40 \mathrm{~nm}$-thick PEDOT:PSS layer was used as the hole-injection layer; $45 \mathrm{~nm}$-thick TAPC layer was used as the hole transporting layer; $5 \mathrm{~nm}$-thick TCTA layer was used as the exciton blocking layer and $55 \mathrm{~nm}$-thick TmPyPB layer as the electron transport layer. From the energy level diagram of two red devices in Fig. S1 in ESI, $\uparrow$ we can see that TCTA and TmPyPB can 


\begin{tabular}{|c|}
\hline LiF $(0.8 \mathrm{~nm}) / A$ I $(80 \mathrm{~nm})$ \\
\hline TmPyPB $(55 \mathrm{~nm})$ \\
\hline M1 or M2:Ir $(\mathrm{pq})_{2}$ acac $(20 \mathrm{~nm})$ \\
\hline TCTA $(5 \mathrm{~nm})$ \\
\hline TAPC $(45 \mathrm{~nm})$ \\
\hline PEDOT:PSS $(40 \mathrm{~nm})$ \\
\hline ITO \\
\hline Glass substrate
\end{tabular}
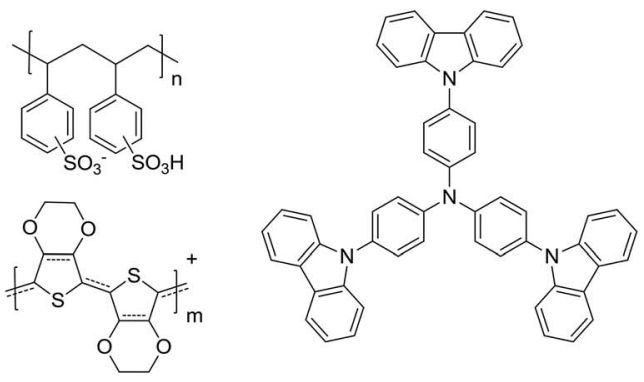

PEDOT:PSS

TCTA

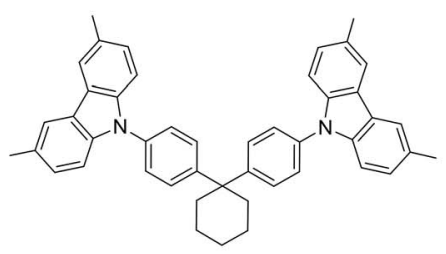

TAPC

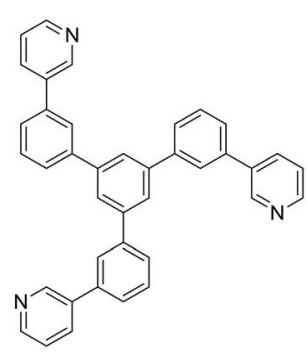

TmPyPb

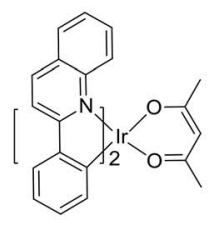

$\operatorname{Ir}(\mathrm{pq})_{2}(\mathrm{acac})$

Fig. 4 The device structure of red devices and organic molecules used in device fabrication.
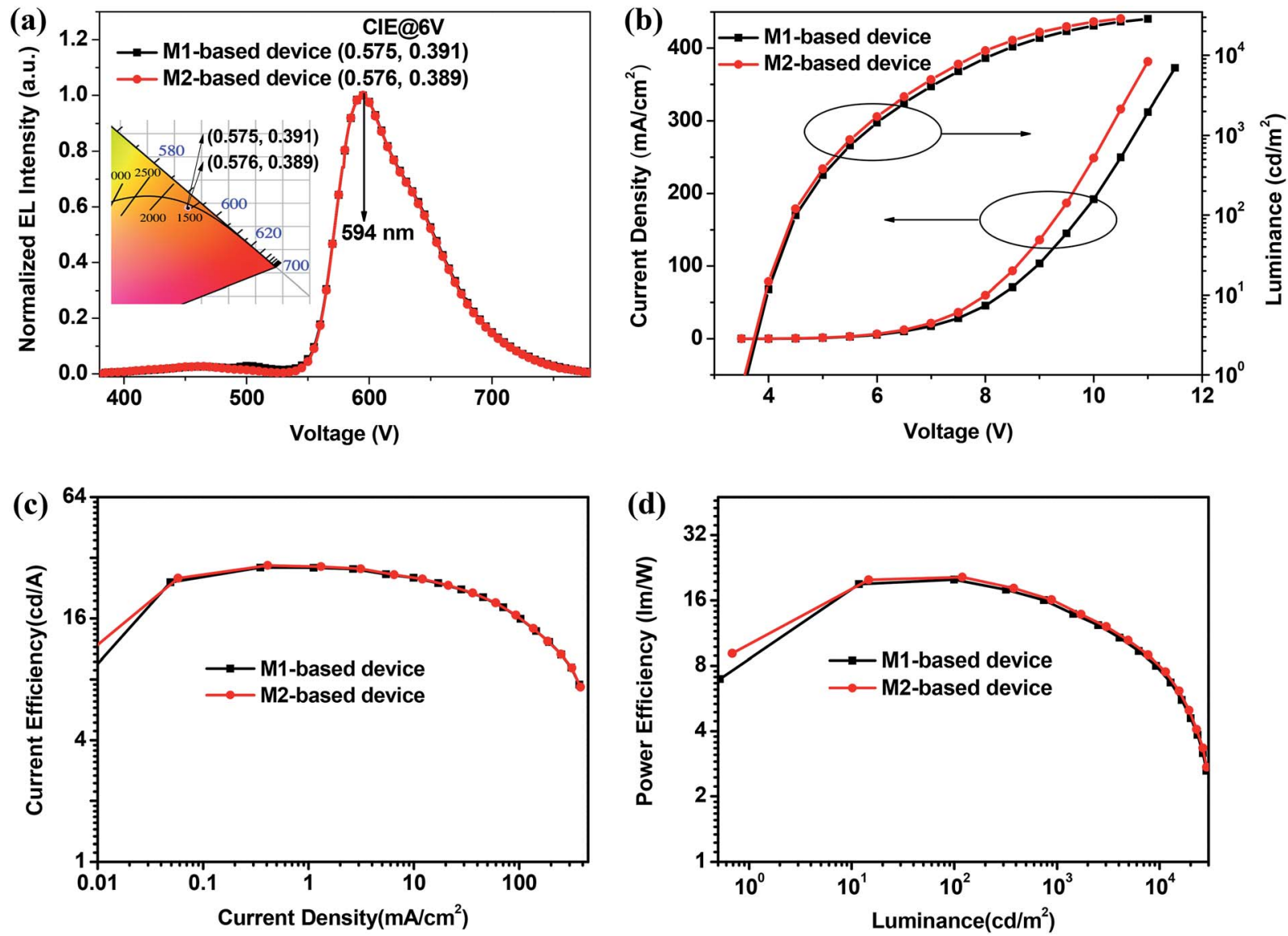

Fig. 5 Normalized EL spectra and CIE coordinates at $6 \mathrm{~V}$ (a), J-V-L (b), CE-J (c), and PE-L (d) characteristic curves for the M1- and M2-based red devices. 
Table 2 The EL performance parameter summary for M1- and M2-based devices

\begin{tabular}{|c|c|c|c|c|c|c|c|}
\hline Device & Host & Voltage $^{a}(\mathrm{~V})$ & \multicolumn{4}{|l|}{ Maximum } & $\operatorname{CIE}^{c}[x, y]$ \\
\hline $\mathrm{R} 2$ & M2 & 3.6 & 29.29 & 20.45 & 15.07 & 28818 & $(0.576,0.389)$ \\
\hline
\end{tabular}

${ }^{a}$ Voltage at a luminance of $>1 \mathrm{~cd} \mathrm{~m}^{-2} \cdot{ }^{b} \mathrm{~L}$ is the abbreviation of luminance. ${ }^{c}$ Measured from the EL spectra at $6 \mathrm{~V}$.

effectively limit carrier recombination zone and generated exciton in EML because of the big LUMO energy barriers of $0.69 \mathrm{eV}$ and $0.81 \mathrm{eV}$ at TCTA/M1 and $\mathbf{M} 2$ interface, a big HOMO energy barrier of $1.20 \mathrm{eV}$ at M1 or M2/TmPyPB interface, and a high triplet levels for TCTA $(2.68 \mathrm{eV})$ and TmPyPB $(2.70 \mathrm{eV})$ than both $\mathbf{M 1}(2.24 \mathrm{eV})$ and $\mathbf{M} 2(2.24 \mathrm{eV}) .{ }^{27}$ Thus, theoretically, both devices R1 and R2 can well reveal the EL performance of compounds $\mathbf{M} 1$ and $\mathbf{M} 2$.

Fig. 5a depicts the normalized EL spectra of M1- and M2based devices at a voltage of $6 \mathrm{~V}$. Clearly, both M1- and M2based devices emit red light, and the EL spectra for two devices are almost completely overlapping with the same peak at $594 \mathrm{~nm}$, and CIE coordinates are $(0.575,0.391)$ and $(0.576$, 0.389) for M1- and M2-based devices, respectively. These are well consistent to the emission characteristic of emitter $\operatorname{Ir}(\mathrm{pq})_{2}$ acac. Meanwhile, from Fig. S2 in ESI, $\uparrow$ it is found that there is almost no EL color shift vary at a wide voltage range of 5-8 $\mathrm{V}$ for two red devices, which indicates (i) the carrier recombination zone and exciton are well confined in the red EML; and the energy in M1 and M2 hosts can be effectively transferred to $\operatorname{Ir}(\mathrm{pq})_{2}$ acac when $\operatorname{Ir}(\mathrm{pq})_{2}$ acac is doped in $\mathbf{M} 1$ and M2 hosts for two red device. The above result preliminarily proved the feasibility of compounds $\mathbf{M 1}$ and $\mathbf{M} 2$ as hosts for red OLEDs.

In fact, the high EL performance for both M1- and M2-based devices further demonstrate that both $\mathbf{M 1}$ and $\mathbf{M} 2$ are excellent host materials for red phosphorescent OLEDs. For example, as shown in Fig. 5b, both M1- and M2-based devices show a relatively low turn-on voltage of $3.6 \mathrm{~V}$, and all achieve very high maximum luminance of $28619 \mathrm{~cd} \mathrm{~m}^{-2}$ for device R1 and 28818 $\mathrm{cd} \mathrm{m}^{-2}$ for device R2. From Fig. 5c, d and S3 in ESI, $\dagger$ both M1and M2-based devices achieve high device efficiency, and the maximum current efficiency (CE), power efficiency (PE), and EQE reach $28.57 \mathrm{~cd} \mathrm{~A}^{-1}, 19.95 \mathrm{~lm} \mathrm{~W}^{-1}$, and $14.66 \%$ for M1based red device and $29.29 \mathrm{~cd} \mathrm{~A}^{-1}, 20.45 \mathrm{~lm} \mathrm{~W}^{-1}$, and $15.07 \%$ for M2-based red device. All above results indicate that these diphenylquinoxaline-based bipolar host materials have potential applications for the development of high-performance red OLEDs. In addition, the performance of red OLEDs in this work are much higher than that in the reported results $(\mathrm{PE}=20.45$ $\operatorname{lm~} \mathrm{W}^{-1}, \mathrm{CE}=29.29 \mathrm{~cd} \mathrm{~A}^{-1}, \mathrm{EQE}=15.07 \%$ vs. $\mathrm{PE}=15.4 \mathrm{~lm} \mathrm{~W}^{-1}$, $\mathrm{CE}=21.9 \mathrm{~cd} \mathrm{~A}^{-1}, \mathrm{EQE}=12.2 \%$ ) showing in Fig. S4, $\dagger$ indicating that the connection ways of electron acceptor/donor moieties have great influence on performance of the host materials (Table 2). ${ }^{34}$

\section{Conclusion}

To conclude, two novel quinoxaline-based bipolar host materials have been rational design and prepared successfully via the Suzuki coupling reaction in high yields for application in red phosphorescent OLEDs. By incorporating the diphenylquinoxaline and carbazole unit as the electron donor and acceptor, meanwhile, the phenyl spacer between the functionalized quinoxaline moiety and carbazole moiety is also introduced to investigate its influence on their photophysical properties. Their thermal, photophysical and electrochemical properties were investigated and discussed in details. The red phosphorescent OLEDs with M1 and M2 as host were fabricated, and it is found both M1 and M2 hosts-based red devices exhibit the outstanding electroluminescent performance. For example, two red devices all realize good red emission with peak at $594 \mathrm{~nm}$, and the maximum luminance and external quantum efficiency reach $28619 \mathrm{~cd} \mathrm{~m}^{-2}$ and $14.66 \%$ for M1-based device and $28818 \mathrm{~cd} \mathrm{~m}^{-2}$ and $15.07 \%$ for M2-based device, indicating that compounds $\mathbf{M 1}$ and $\mathbf{M} 2$ synthesized in this work have the potential applications in the development of high performance red and white OLEDs.

\section{Conflicts of interest}

There are no conflicts to declare.

\section{Acknowledgements}

Zilong Feng and Zhixiang Gao contributed equally to this work. The authors are grateful for the financial support of the National Natural Science Foundation of China (21872088, 11874245), Shanxi Province Science and Technology Key Project (201703D121037-2), Datong City Science and Technology Research Project (2018018).

\section{References}

1 C. W. Tang and S. A. VanSlyke, Appl. Phys. Lett., 1987, 51, 913-915.

2 S. Reineke, F. Lindner, G. Schwartz, N. Seidler, K. Walzer, B. Lussem and K. Leo, Nature, 2009, 459, 234-238.

3 Y. Chang, Y. Song, Z. Wang, M. Helander, J. Qiu, L. Chai, Z. Liu, G. Scholes and Z. Lu, Adv. Funct. Mater., 2013, 23, 705-712. 
4 Y. Miao, K. Wang, L. Gao, H. Wang, F. Zhu and B. Xu, J. Mater. Chem. C, 2018, 6, 9811-9820.

5 H. Sasabe and J. Kido, J. Mater. Chem. C, 2013, 1, 1699-1707. 6 P. Tao, Y. Miao, H. Wang, B. Xu and Q. Zhao, Chem. Rec., 2018, 18, 1-32.

7 V. Sree, A. Maheshwaran, H. Kim, H. Park, Y. Kim, J. Lee, M. Song and S. Jin, Adv. Funct. Mater., 2018, 28, 1804714.

8 X. Tang, X. Liu, Z. Jiang and L. Liao, Adv. Funct. Mater., 2019, 29, 1807541.

9 T. H. Han, Y. Lee, M. R. Choi, S. H. Woo, S. H. Bae, B. H. Hong, J. H. Ahn and T. W. Lee, Nat. Photonics, 2012, 6, 105-110.

10 H. Uoyama, K. Goushi, K. Shizu, H. Nomura and C. Adachi, Nature, 2012, 492, 234-238.

11 Y. Miao, K. Wang, L. Gao, B. Zhao, Z. Wang, Y. Zhao, A. Zhang, H. Wang, Y. Hao and B. J. Xu, J. Mater. Chem. C, 2018, 6, 1853-1862.

12 C. L. Ho and W. Y. Wong, Coord. Chem. Rev., 2013, 257, 1614-1649.

13 L. Ying, C. L. Ho, H. B. Wu, Y. Cao and W. Y. Wong, Adv. Mater., 2014, 26, 2459-2473.

14 X. L. Yang, G. J. Zhou and W. Y. Wong, J. Mater. Chem. C, 2014, 2, 1760-1778.

15 P. Tao, Y. Zhang, J. Wang, L. Wei, H. Li, X. Li, Q. Zhao, X. Zhang, S. Liu, H. Wang and W. Huang, J. Mater. Chem. C, 2017, 5, 9306-9314.

16 R. Ding, J. Feng, F. X. Dong, W. Zhou, Y. Liu, X. L. Zhang, X. P. Wang, H. H. Fang, B. Xu, X. B. Li, H. Y. Wang, S. Hotta and H. B. Sun, Adv. Funct. Mater., 2017, 27, 1604659.

17 J. Lin, Y. Wang, P. Gnanasekaran, Y. Chiang, C. Yang, C. Chang, S. Liu, G. Lee, P. Chou, Y. Chi and S. Liu, Adv. Funct. Mater., 2017, 27, 1702856.

18 M. A. Baldo, D. F. O'Brien, Y. You, A. Shoustikov, S. Sibley, M. E. Thompson and S. R. Forrest, Nature, 1998, 395, 151154.

19 Y. R. Sun, N. C. Giebink, H. Kanno, B. W. Ma, M. E. Thompson and S. R. Forrest, Nature, 2006, 440, 908912.

20 J. Lee, H. F. Chen, T. Batagoda, C. Coburn, P. I. Djurovich, M. E. Thompson and S. R. Forrest, Nat. Mater., 2016, 15, 92-98.

21 W. Y. Wong and L. J. Ho, J. Mater. Chem., 2009, 19, 44574482.

22 W. Y. Wong and C. L. Ho, Coord. Chem. Rev., 2009, 253, 1709-1758.
23 P. Tao, Q. Zhao, S. Jing, J. Wang, Z. Lv, L. Chen and H. Wang, Chin. J. Lumin., 2013, 34, 816-823.

24 P. Tao, W. Li, J. Zhang, S. Guo, Q. Zhao, H. Wang, B. Wei, S. Liu, X. Zhou, Q. Yu, B. Xu and W. Huang, Adv. Funct. Mater., 2016, 26, 881-894.

25 Y. Miao, P. Tao, L. Gao, X. Li, L. Wei, S. Liu, H. Wang, B. Xu and Q. J. Zhao, J. Mater. Chem. C, 2018, 6, 6656-6665.

26 C. Fan and C. L. Yang, Chem. Soc. Rev., 2014, 43, 6439-6469.

27 Y. Miao, K. Wang, L. Gao, B. Zhao, H. Wang and F. J. Zhu, J. Mater. Chem. C, 2018, 6, 8122-8134.

28 J. J. Guo, X. L. Li, H. Nie, W. W. Luo, S. F. Gan, S. M. Hu, R. R. Hu, A. J. Qin, Z. J. Zhao, S. J. Su and B. Z. Tang, Adv. Funct. Mater., 2017, 27, 1606458.

29 L. Gao, P. Tao, Y. Miao, W. Jia, Y. Zhao, H. Wang and B. Xu, Tetrahedron Lett., 2018, 59, 2095-2098.

30 Y. Miao, K. Wang, B. Zhao, L. Gao, Y. Wang, H. Wang, B. Xu and F. J. Zhu, J. Mater. Chem. C, 2017, 5, 12474-12482.

31 X. Cai and S. Su, Adv. Funct. Mater., 2018, 28, 1802558.

32 H. Li, P. Tao, Y. Xu, X. Zhang, S. Liu and Q. Zhao, Tetrahedron Lett., 2018, 59, 1748-1751.

33 C. H. Fan, P. P. Sun, T. H. Su and C. H. Cheng, Adv. Mater., 2011, 23, 2981-2985.

34 M. Hu, Q. Xu, Y. Jiang, H. Mu, L. Gao, P. Hu, J. Huang and J. Su, Dyes Pigm., 2018, 150, 185-192.

35 Y. Miao, P. Tao, K. Wang, H. Li, B. Zhao, L. Gao, H. Wang, B. Xu and Q. Zhao, ACS Appl. Mater. Interfaces, 2017, 9, 37873-37882.

36 P. Tao, Y. Miao, Y. Zhang, K. Wang, H. Li, L. Li, X. Li, T. Yang, Q. Zhao, H. Wang, S. Liu, X. Zhou, B. Xu and W. Huang, Org. Electron., 2017, 45, 293-301.

37 P. Tao, Y. Miao, K. Wang, H. Li, Q. Zhao, H. Wang, J. Li, B. Xu and W. Huang, Tetrahedron Lett., 2017, 58, 3598-3601.

38 Z. Feng, P. Tao, L. Zou, P. Gao, Y. Liu, X. Liu, H. Wang, S. Liu, Q. Dong, J. Li, B. Xu, W. Huang, W. Wong and Q. Zhao, ACS Appl. Mater. Interfaces, 2017, 9, 28319-28330.

39 Y. Miao, K. Wang, B. Zhao, L. Gao, P. Tao, X. Liu, Y. Hao, H. Wang, B. Xu and F. Zhu, Nanophotonics, 2018, 7, 295-304.

40 W. Li, J. Y. Li, D. Liu and Q. Jin, ACS Appl. Mater. Interfaces, 2016, 8, 22382-22391.

41 H. Xu, P. Sun, K. Wang, J. Li, F. Wang, Y. Miao, H. Wang, B. Xu and W. Wong, J. Mater. Chem. C, 2017, 5, 4455-4462.

42 K. Wang, P. Sun, H. Xu, J. Li, F. Wang, Y. Miao, T. Yang, H. Wang, B. Xu and W. Wong, Dyes Pigm., 2017, 143, 25-32. 